Artigo Original

\title{
Crenças de autoeficácia de licenciandos em Educação Física
}

\author{
Afonsa Janaína da Silva ${ }^{1}$ \\ Roberto Tadeu laochite ${ }^{2}$ \\ Roberta Gurgel Azzi ${ }^{3}$ \\ ${ }^{1}$ FEF da Universidade São Francisco, Bragança Paulista, SP, Brasil \\ ${ }^{2}$ DEF da Universidade de Taubaté, Taubaté, SP; ESEFIC, Cruzeiro, SP, Brasil \\ ${ }^{3}$ FE da Universidade Estadual de Campinas, Campinas, SP, Brasil
}

\begin{abstract}
Resumo: Os julgamentos feitos pelos professores acerca das próprias capacidades para ensinar são importantes para a tomada de decisão e para as ações que se seguirão ao longo do processo ensino e aprendizagem na docência em Educação Física. Com objetivo de investigar as crenças de autoeficácia de licenciandos em Educação Física, 159 alunos das $3^{\underline{a}}$ e $4^{\text {a }}$ séries de cursos de licenciatura em Educação Física responderam a Escala de autoeficácia de professor de Educação Física e um questionário de caracterização. Os participantes se perceberam com um nível elevado de auto-eficácia, reconhecendo a importância da experiência direta de docência durante a formação. Esses resultados fornecem orientações para o planejamento de estratégias de ensino face à construção de crenças de auto-eficácia elevadas durante o processo formativo, haja vista que as conseqüências dessa crença estão associadas com os comportamentos de engajamento e envolvimento na tarefa de ensinar.
\end{abstract}

Palavras-chave: Auto-eficácia. Licenciando. Educação Física.

\section{Physical Education student teacher's self-efficacy beliefs}

Abstract: The judgments made by teachers about their own abilities to teach are important for decision making and the actions that will follow over the teaching and learning process in teaching in Physical Education. In order to investigate self-efficacy beliefs of student teachers in Physical Education, 159 students from 3rd and 4th grades of undergraduate courses in Physical Education responded to Physical Educator's Self-efficacy scale and a questionnaire. Participants are realized with a high level of self-efficacy, recognizing the importance of mastery experiences of teaching during undergraduate classes. These results provide guidance for planning strategies to address the construction of high teaching self-efficacy beliefs during the preparation process, considering that the consequences of such beliefs are associated with engagement and involvement in the task of teaching.

Key Words: Self-efficacy. Undergradutate. Physical Education

\section{Introdução}

As experiências de primeira docência representam um importante momento na formação inicial de forma a possibilitar, dentro de um contexto relativamente protegido, que 0 estudante possa colocar em prática os conhecimentos e competências desenvolvidas no decorrer desse processo.

Segundo Caíres e Almeida (2001) esse momento é composto por inúmeros desafios e mudanças pertinentes à passagem para a atuação profissional e pode causar impacto não apenas nas dimensões técnicas da atuação, como também, nas crenças pessoais do futuro professor sobre sua condição para assumir a posição de professor. Dentre estas crenças encontra-se, em especial, àquela relacionada à sua eficácia para ensinar.

As pesquisas já desenvolvidas sobre autoeficácia para ensinar apontam que ao alcançar um grau elevado de eficácia percebida os professores podem ter uma mudança considerável no modo como encaram as adversidades da profissão e acabam por transmitirem isso aos seus alunos (BZUNECK, 2000).

Professores com elevado nível de autoeficácia apresentam-se mais motivados e acabam gerando motivação também aos seus alunos acarretando mudanças no comportamento dos mesmos. Outros comportamentos identificados quando na atuação destes professores são: utilização de métodos de ensino diferentes, diversificação na seleção de conteúdos e incentivo à participação de todos (AZZI, POLYDORO, BZUNECK, 2006; BZUNECK, 2000; ROSS, 1995).

Nessa direção, é possível apontar a importância do desenvolvimento destas crenças de eficácia docente no contexto da formação inicial, pois elas regulam a percepção do aluno sobre sua capacidade de lidar com situações que 
envolvem sua própria aprendizagem, bem como lidar com o sucesso e o fracasso nas diferentes tarefas que compõe tal processo de formação.

A literatura tem assinalado que os estágios iniciais de prática docente são fundamentais para a construção de um senso de eficácia positivo e promotor de níveis elevados de motivação e comprometimento com a tarefa de ensinar (LIN, GORRELL, TAYLOR, 2002).

O estudo e a avaliação das crenças de autoeficácia no contexto acadêmico, mais especificamente de futuros professores, tornamse relevante uma vez que possibilita ampliar o conhecimento das características envolvidas no processo ensino e aprendizagem.

Relacionado com o estabelecimento de condições promotoras de auto-eficácia, essa condição é desejável, uma vez que um bom desempenho nas primeiras experiências de docência pode representar a continuidade e a crescente intensidade dos esforços em vencer desafios, fatos que abrem novas perspectivas para o aperfeiçoamento da formação inicial dos professores.

$O$ pressuposto que governa 0 presente trabalho é que, ao se investigar crenças de autoeficácia de futuros professores para a docência, identificar-se-á pistas que possam contribuir para um repensar sobre as estratégias desenvolvidas ao longo do processo de formação com relação à preparação para ensinar.

Assim, a presente pesquisa busca identificar e analisar a percepção de auto-eficácia de futuros professores de Educação Física. São questões norteadoras do estudo: qual é o nível de autoeficácia de futuros professores de Educação Física? Há diferenças de nível de autoeficácia em função do gênero e da idade? Partindo do fato de que a grade curricular dos cursos de formação em Educação Física é composta por disciplinas de diferentes naturezas, em quais delas os futuros professores reconhecem mais possibilidades de vivenciar situações de prática docente?

Vinculados às preocupações e pesquisas na área da formação profissional, vários estudos sobre a temática da primeira docência têm sido desenvolvidos sob diferentes olhares teóricos. É sob a perspectiva teórica da auto-eficácia proposta por Albert Bandura que a presente investigação está alicerçada.

\section{Autoeficácia do professor}

Elementos que integram a perspectiva teórica da autoeficácia docente apareceram inicialmente nos estudos de Denham e Michael em 1981 e de Ashton e Webb em 1982, os quais desenvolveram modelos multidimensionais de eficácia do professor.

Ao revisar a história da construção do construto da eficácia do professor, Fives (2003) ressalta a importância de se compreender 0 construto na linha de investigação teórica de Bandura, no que diz respeito ao seu papel mediador na motivação, persistência e esforço.

A autoeficácia docente é definida como sendo um julgamento que o professor faz acerca das próprias capacidades para atingir resultados de engajamento e aprendizagem dos alunos, inclusive aqueles desmotivados para aprender (TSCHANNEN-MORAN, WOOLFOLK HOY, 2001).

Para Bandura (1986) possuir conhecimentos e algumas habilidades não basta para alcançar êxito na realização de determinadas ações. Reconhecer a confiança na sua própria capacidade de ensinar é que constitui um requisito fundamental para alcançar objetivos pretendidos. Segundo ele, as conseqüências de se possuir uma sólida crença de autoeficácia para ensinar são: mudança no estabelecimento de metas; mudança no esforço aplicado para executar uma tarefa; persistência, apesar das dificuldades encontradas no caminho e na postura perante o fracasso.

Azzi, Polydoro e Bzuneck (2006) afirmam que professores com altos níveis de autoeficácia têm maiores condições de construir ambientes favoráveis à aprendizagem, onde os alunos são participantes ativos e práticas inovadoras de ensino parecem ocorrer.

É possível relacionar, ainda, o elevado grau de autoeficácia do professor com transformações no comportamento de seus alunos como: melhores desempenhos, em diversas matérias; incremento da crença de autoeficácia nos próprios alunos em conseqüência as modificações em sua motivação. Professores com percepções baixas de autoeficácia tendem a evitar atividades e até de planejá-las, quando a considera acima de suas capacidades, são menos persistentes no trato com alunos portadores de dificuldades e mostram-se menos dispostos a inovações (BZUNECK, 2000).

É Bzuneck quem nos alerta que os fatores que mais afetam as crenças de autoeficácia dos professores são: o comportamento $e$ as realizações de seus alunos; as séries escolares; 0 tempo de exercício da profissão; e a idade cronológica. Esses fatores são significativos no 
incremento ou diminuição das crenças dos professores e poderão ser responsáveis por mudanças a verificar-se a qualquer momento.

Ross (1995) ao investigar as influências da autoeficácia do professor, para a aprendizagem nas escolas, ressaltou o engajamento e esforço apresentado por estes professores e sugere que as escolas desenvolvam trabalhos pra incrementar a crença em seus professores.

Outro foco de investigação nos estudos com a auto-eficácia docente tem sido a compreensão sobre o desenvolvimento da crença ao longo do tempo, isto é, desde os períodos de formação inicial para a docência até a prática experiente, adquirida ao longo dos anos desse exercício.

Tschannen-Moran e Woolfolk Hoy (2007) afirmam que essas crenças são mais flexíveis, isto é, maleáveis no início da aprendizagem quando comparadas com as crenças de professores mais experientes e, parte dessa maleabilidade pode estar relacionada a uma série de fatores, entre eles, a pouca quantidade de experiências práticas exercidas diretamente no contexto específico de ensino. Parece haver alguma evidência de que, em função das diferentes fontes de informação como, por exemplo, maior exposição a modelos e maior quantidade de informação por meio da persuasão social nos períodos de formação, as crenças relacionadas à tarefa de ensino possam ser modificadas nesse período (WATTERS e GINNS, 1995).

No início da carreira, por exemplo, as crenças de autoeficácia dos professores parecem estar mais relacionadas com as reações fisiológicas e estados emocionais advindos do "choque" com a realidade. Professores novatos que se percebem confiantes para ensinar, vivenciam menos sentimentos de estresse e ansiedade e mais sentimentos de satisfação e otimismo (TSCHANNEN-MORAN, WOOLFOLK HOY e HOY, 1998).

Mais especificamente durante o processo de formação inicial, Woolfolk Hoy (2004) aponta que a experiência direta de ensino vivenciada neste período e aquela vivida nos anos iniciais de atuação profissional exercem grande influência no desenvolvimento da autoeficácia do professor.

No caso da formação em Educação Física, por exemplo, inúmeras são as oportunidades de se vivenciar diretamente a docência, sobretudo nas chamadas disciplinas de caráter didáticopedagógicas e nas disciplinas orientadas às atividades, conforme assinalam Pérez Gallardo (1998), Tani (1996). Para esses autores, essas disciplinas são de natureza teórico-práticas que possibilitam a interrelação entre teoria e prática na área e são responsáveis pela transmissão de conhecimentos relacionados com métodos e técnicas de ensino.

A teoria da autoeficácia demonstra que os primeiros anos de docência podem representar uma fase crítica ao desenvolvimento da autoeficácia do professor durante o percurso de sua atuação profissional, devido a maleabilidade da crença no estágio inicial. Bandura (1997) reafirma a existência de quatro fontes principais que se integram na constituição da crença de autoeficácia docente. São elas: a) experiências diretas - situações vivenciadas pelo sujeito; b) experiências de observação - via modelação; c) persuasão social e d) estados afetivos e fisiológicos decorrentes das experiências vividas no domínio avaliado.

Segundo Woolfolk Hoy e Burke Spero (2005) o impacto das crenças implementadas nas experiências iniciais de docência é maior que as implementadas quando os professores já estão atuando no campo de trabalho. Lin, Gorrell e Taylor (2002) num estudo com estudantes em formação para a docência alegam que as crenças de eficácia destes futuros professores foram influenciadas pelo contexto acadêmico dos cursos de formação em que estavam inseridos.

Os saberes, as possibilidades e a forma de atuar que os professores em formação adotam durante sua formação são mediadas pelo o que eles pensam e acreditam e, no eixo desta mediação, encontram-se as autocrenças destes professores em formação, principalmente a autoeficácia (GIBBS, 2003). Para esse autor, os programas de formação de professores devem dar subsídios para que os professores possam exercer autocontrole sobre seus pensamentos, emoções e ações durante o processo de ensino, dando assim atenção especial ao desenvolvimento e exercício da autoeficácia nas suas atividades de ensino.

A partir desses apontamentos sobre a importância da autoeficácia no contexto acadêmico, em especial na formação de futuros professores, a presente pesquisa buscou identificar e analisar a percepção de autoeficácia de estudantes em formação para a docência em Educação Física.

\section{Método}

Participaram desse estudo 159 estudantes de graduação, sendo $43,9 \%$ do gênero feminino e $56,1 \%$ masculino. A variação da faixa etária dos participantes foi de 19 a 48 anos, obtendo como média 25,4 anos e desvio padrão de 5,58 anos. 
Todos engajados em cursos de graduação em Licenciatura em Educação Física das $3^{\underline{a}}$ e $4^{\underline{a}}$ séries de quatro instituições privadas de ensino superior.

Foi utilizada a Escala de Autoeficácia de professor de Educação Física proposta por Polydoro, Winterstein, Azzi, do Carmo e Venditti Jr (2004). A escala utilizada na presente investigação é do tipo Likert, de 6 pontos, com 24 itens distribuídos em dois fatores (alfa de Cronbach $=0,937)$. $O$ primeiro fator foi denominado de eficácia na intencionalidade da ação docente (fator 1) e representou a crença do professor na capacidade de mediar o ensino e mobilizar o estudante para a realização da atividade (alfa de Cronbach $=0,913$ ). São exemplos de itens desse fator: "Quanto você pode fazer para motivar alunos(as) que demonstram baixo interesse na atividade?", "Quanto você pode ajudar seus alunos(as) a dar valor à aprendizagem?", entre outros. O segundo fator denominado de eficácia no manejo da classe (fator 2) representou a crença do professor para lidar, gerenciar os múltiplos aspectos do cotidiano da aula (alfa de Cronbach= 0,863). "Quanto você pode fazer para lidar com os alunos mais difíceis?", "Quão bem você pode estabelecer rotinas para manter as atividades acontecendo de forma tranqüila?" são alguns exemplos de itens que compõem esse fator. Segundo os autores da escala proposta para a versão brasileira, "a organização em dois fatores indica maior nível de interpretação dos resultados gerando [...] uma definição das tarefas envolvidas na ação do professor de Educação Física escolar" (POLYDORO, S.; WINSTERSTEIN, P. J.; AZZI, R. G.; DO CARMO, A. P.; VENDITTI JR, R., 2004, p.335).

Tabela 1. Descrição estatística dos níveis de autoeficácia dos participantes.

\begin{tabular}{lccccc}
\hline \multicolumn{1}{c}{ Dimensões } & N & Mínimo & Máximo & Média & Desvio Padrão \\
\hline Intencionalidade docente & 145 & 3,36 & 6,00 & 4,99 & 0,54 \\
Manejo da classe & 152 & 3,50 & 6,00 & 4,80 & 0,59 \\
\hline Total & 142 & 3,46 & 6,00 & 4,91 & 0,54 \\
\hline
\end{tabular}

\section{Resultados}

Como podemos ver na Tabela 1 , os dados apontam que de modo geral os participantes do nosso estudo percebem-se com um nível de autoeficácia elevado, os resultados obtidos mostram, em relação as dimensões propostas previamente pelos autores da escala, os seguintes valores: a média da pontuação do grupo na escala para a variante intencionalidade docente foi de 4,99 e para a variante manejo da classe foi de 4,79 , vale lembrar que a pontuação máxima da escala é de 6 pontos.

Foi realizada também a análise estatística do nível de autoeficácia dos participantes para cada item da escala. Os dados encontrados
Para a coleta dos dados relativos ao participante foi utilizado um questionário de caracterização contendo questões de ordem demográfica e de contextualização da formação. São exemplos dessas questões: "Você já teve alguma experiência como docente?", "Quais as disciplinas da graduação você reconhece como promotoras de experiência docente"? Com esses questionamentos espera-se identificar possíveis situações de experiências diretas que podem, de alguma forma, fornecer pistas para a continuidade da pesquisa no que tange à investigação da construção da crença de autoeficácia de futuros professores, ainda no momento de formação.

Juntamente com os instrumentos foi apresentado aos participantes 0 termo de consentimento livre e esclarecido, que após a explicação dos objetivos da pesquisa foi assinado por todos os participantes. Das instituições contatadas, quatro instituições particulares de ensino superior em Educação Física autorizaram a coleta dos dados.

A aplicação dos instrumentos ocorreu em uma única sessão, de forma coletiva e separadamente em cada instituição, durante o período de aula e tendo a duração de 30 minutos aproximadamente. Após a aplicação, todos os resultados coletados pela escala foram transferidos para o programa estatístico Statistical Package for the Social Sciences, (SPSS, 2003). Os tipos de análises utilizadas foram: análise descritiva - freqüências, T-Test e Anova. demonstram que para dimensão intencionalidade da ação docente os itens da escala onde os participantes apresentam-se mais autoeficazes foram: item 6 (5,33 pontos) - Quanto você pode fazer com que os alunos (as) acreditem que podem realizar bem as atividades? e item 9 (5,18 pontos) - Quanto você pode ajudar seus alunos (as) a dar valor a educação? Os itens que apresentaram menor autoeficácia foram: item 15 (4,62) - Quanto você pode fazer para acalmar um aluno (a) que é perturbador (a) ou barulhento (a)? e item 17 (4,79 pontos) - O que você pode fazer para ajustar suas atividades ao apropriado nível individual dos alunos (as)? 
Tabela 2. Descrição estatística dos níveis de autoeficácia dos participantes em relação ao gênero.

\begin{tabular}{ccccccc}
\hline Dimensões & Gênero & N & Média & Desvio Padrão & F & Sig \\
\hline \multirow{2}{*}{ Intencionalidade docente } & feminino & 64 & 4,90 & 0,51 & \multirow{2}{*}{0,46} & 0,08 \\
& masculino & 79 & 5,05 & 0,55 & & \\
\multirow{2}{*}{ Manejo da classe } & feminino & 66 & 4,68 & 0,58 & \multirow{2}{*}{0,37} & $0,04^{*}$ \\
& masculino & 84 & 4,88 & 0,58 & & \\
\hline \multirow{2}{*}{ Total } & feminino & 63 & 4,82 & 0,51 & \multirow{2}{*}{0,58} & 0,09 \\
& masculino & 77 & 4,97 & 0,55 & & \\
\hline
\end{tabular}

Para dimensão manejo da classe os itens da escala onde os participantes apresentam-se mais autoeficazes foram: item $21(4,92)$ - Quão bem você pode responder um aluno desafiador? e item $24(5,18)$ - Quão bem você pode providenciar desafios apropriados para alunos (as) muito capazes? Já, os itens da escala em os participantes apresentam-se menos autoeficazes foram: item 16 (4,51) - Quão bem você pode estabelecer um sistema de gerenciamento da aula com cada grupo de alunos (as)? e item $22(4,62)$ - Quanto você pode auxiliar a família a ajudar os filhos a irem bem em atividade física/ esportivas?

Em relação ao gênero a diferença entre as médias dos gêneros para a dimensão intencionalidade da ação não foi significativa, porém em relação a dimensão manejo da classe os dados apresentam uma diferença significativa, ou seja sig < 0,05 (ver Tabela 2) favorecendo o gênero masculino que para esta dimensão demonstraram possuir níveis de autoeficácia mais elevados. Os dados observados para esta variável foram: a média da pontuação do grupo na escala para a variante intencionalidade docente para o gênero feminino foi de 4,9 e para o gênero masculino de 5,0 e para a variante manejo da classe para o gênero feminino foi de 4,7 e para $o$ gênero masculino de 4,9 , o que representa um elevado nível de autoeficácia.

Tabela 3. Caracterização da natureza das disciplinas em que os participantes reconheceram possibilidades de prática docente

\begin{tabular}{lcc}
\hline \multicolumn{1}{c}{ Disciplinas } & Respostas Múltiplas & $\%$ \\
\hline Disciplinas predominantemente práticas & 84 & 52,8 \\
Disciplinas práticas e teóricas & 58 & 35,8 \\
Não respondeu & 16 & 11,4 \\
\hline Total & 159 & 100 \\
\hline
\end{tabular}

Classificamos as disciplinas onde os participantes reconhecem a possibilidade de experiências práticas em duas categorias: disciplinas predominantemente práticas, ou seja, aquelas disciplinas de orientação didáticopedagógica e de orientação às atividades; e as disciplinas predominantemente teóricas - aquelas de orientação acadêmica (PÉREZ GALLARDO, 1998). Desta forma as respostas dos participantes configuraram-se da seguinte forma: $35,8 \%$ dos participantes identificaram a possibilidade de experiência prática em disciplinas de ambas categorias, $52,8 \%$ somente em disciplinas predominantemente práticas e $11,4 \%$ dos participantes não responderam a questão.

\section{Discussão}

A mensuração do nível de autoeficácia docente tem, entre outras vantagens, a possibilidade de fornecer dados importantes para a predição de comportamentos do docente, com vistas ao planejamento de ações que possam desencadear resultados satisfatórios em contextos de ensino-aprendizagem.

O nível elevado de autoeficácia docente apresentado pelos participantes do estudo se mostrou semelhante aos já encontrados nos estudos de Looney (2003), Venditti Jr. (2005) e Tschannen-Moran e Woolfolk Hoy (2002). Os valores encontrados no presente estudo retrataram ligeira vantagem do fator intencionalidade da ação docente - relacionado com a capacidade do professor de mediar o ensino com o aluno e de motivá-lo à realização das atividades. Isso pode estar representando que, para o grupo investigado, parece haver mais segurança em se julgar capaz na direção de ações que reforcem 0 papel mediador do 
professor do que no papel de administrar manejar - o controle da sala.

Dadas algumas características das aulas e do contexto - jogos, atividades dinâmicas, alunos em movimento, outros desmotivados, material etc. podem de certa forma, também influenciar nessa diferença, no sentido de que, gerenciar isso pode tornar-se mais desafiador em algumas condições e isso pode ter contribuído para a queda no valor dessa dimensão. No entanto, é necessário reiterar que ambos os fatores estiveram acima da média escalar.

No que diz respeito à diferença significativa encontrada para o gênero masculino no fator relacionado com o manejo da sala, não foi encontrado na literatura dados que pudessem explicar essa diferença, conforme assinalaram Gencer e Cakiroglu (2007), ainda que os homens possam ser mais rígidos, controladores e autoritários conforme apontam os autores Martin e Yin (1997 citados por GENCER E CAKIROGLU, 2007).

As diferentes possibilidades de atuação destes estudantes, se trabalhadas, podem ser grandes auxiliadoras ao incremento da crença de autoeficácia de futuros professores. Experiências de êxito, fracasso e as possíveis trocas de experiência podem ser fontes para o julgamento destes profissionais sobre suas capacidades, influenciando assim o julgamento que estão construindo sobre a capacidade para ensinar.

Quando analisamos as respostas dos participantes das questões relacionadas com a prática docente no decorrer do curso enxergamos uma tendência em reconhecerem somente em disciplinas que enfocam os conhecimentos tidos como específicos da Educação Física, a vivência como docente. De certa forma, isso serve como alerta para cursos de formação inicial sobre importância de se pensar em planejamentos de situações pedagógicas que envolvam a participação do estudante exercendo o papel do professor, como um exercício que possibilite a vivência (ainda que simulada) de situações que envolvam liderança, manejo, incentivo e comunicação junto à própria turma ou em situações mais reais como, por exemplo, com um grupo de crianças ou adolescentes.

Sobre isso, Rangel-Betti e Galvão (2001) afirmaram que o aluno de graduação necessita ser inserido na prática o quanto antes em sua formação, para que possa construir e comparar estratégias de ação, formas de pesquisa, teorias e categorias de compreensão. Porém essas devem ser realizadas de forma a favorecer 0 aluno a refletir antes, após e durante a prática de ensinar, para tanto todo o corpo docente deveria estar engajados neste processo. A prática reflexiva é uma possibilidade auxílio a esta questão, pois proporciona ao futuro professor, mesmo em aulas predominantemente teóricas, ter experiências práticas através da reflexão sobre a mesma, imaginando situação problemas e resoluções.

Pereira, Almeida e Azzi (2002) apontam também o ensino por meio da solução de problemas como uma possibilidade de aproximação da teoria e prática, a partir da criação de uma ambiente de pesquisa que propicie a aproximação gradativa do professor em formação com a realidade, no qual a articulação teoria prática seja ponto fundamental a compreensão da realidade.

Em que pesem problemas gerados pela organização curricular nos cursos de Educação Física o fato é que os resultados deste estudo evidenciam um conjunto de alunos que se perceberam bastante eficazes para o ensino e este é um resultado importante, pois, como vimos anteriormente professores com níveis altos de autoeficácia percebida promovem ambientes mais favorecedores de aprendizagem.

Observando os resultados desse estudo, atentamos para importância de se repensar, no contexto de formação, ações que possam incrementar a autoeficácia dos professores em formação para a inovação e aperfeiçoamento de sua atuação, bem como, para o gerenciamento de aula e a extensão de sua atuação ao ambiente familiar dos alunos, pois estes foram os itens nos quais os participantes do estudo apresentaram menores níveis de autoeficácia.

Por outro lado, vale ainda destacar que estudos dessa natureza podem ser de extrema importância para ajudar a encontrar pistas, como as destacadas a seguir, que possam servir de referências nas reflexões sobre os contextos de formação oferecidos pelos cursos de graduação. Pelos resultados encontrados pode-se indicar as seguintes pistas para trabalhar pelo fortalecimento de crenças de autoeficácia de futuros professores de Educação Física:

- Manter o oferecimento de situações que promovam a experiência direta na ação docente com vistas à aquisição de competências e habilidades relacionadas com $o$ ensino e fortalecimento da crença de autoeficácia pela fonte da experiência direta;

- Otimizar as situações de aprendizagem por observação por meio de modelos diversos - os próprios licenciandos, vídeos, o professor da disciplina etc. com o objetivo de fortalecer a aprendizagem por modelação; 
- Promover feedback sob a forma de elogios, correções, quando na vivência de experiências de docência durante a disciplina;

- Evidenciar as faces 'práticas' nas situações onde o desafio de enxergar o contexto da docência esteja mais distante, ou seja, levar o estudante a refletir sobre a prática docente em todas as situações da formação, para além daquelas em que a vivência prática seja evidenciada.

Para finalizar este trabalho é necessário apontar as limitações do estudo no que tange à fase em que os participantes se encontram, isto é, ainda em formação, o que de certa forma, pode ter influenciado nas respostas dadas uma vez dizer que embora os resultados encontrados anunciem um panorama positivo quando confrontados com a literatura sobre autoeficácia docente vale a pena lembrarmos que outros estudos precisam ser feitos para que 0 aprofundamento e detalhamento de sua contribuição na realidade dos cursos de formação em Educação Física.

\section{Referências}

AZZI, R.G., POLYDORO, S.A.J., BZUNECK, J.A. Considerações sobre a Auto-eficácia Docente. In: AZZI, R.G. e POLYDORO, S.A.J. (Orgs.) Autoeficácia em diferentes contextos. Campinas, SP: Editora Alínea, 2006. p.149-159.

\section{BANDURA, A. Social foundations of thought} and action: a social cognitive theory. Englewood Cliffs: Prentice Hall, 1986.

\section{BANDURA, A. (Ed.). Self-efficacy in changes} societies. UK: Cambridge University Press, 1997.

BZUNECK, J. A. As crenças de auto-eficácia dos professores. In: SISTO, F.; OLIVEIRA, G. C.; FINI, L. D. T. (org.). Leituras de psicologia para formação de professores. Petrópolis: Vozes, Bragança Paulista: UEF, 2000, p117-134.

CAÍRES, S.; ALMEIDA, L. S. O estágio como um espaço de desenvolvimento de competências pessoais e profissionais: o papel da supervisão. In GONÇALVES, A.; ALMEIDA, L. S.;

VASCONCELOS, R.; CAÍRES, S. Da universidade para o mundo do trabalho: desafios para um diálogo. 1. ed. Portugal: Universidade do Minho, 2001.

FIVES, H. What is Teacher Efficacy and How does it Relate to Teachers' Knowledge? A Theoretical Review. Paper presented at the American Education Research Association Annual Conference, Chicago, April, 2003.

GENCER, A. S., CAKAKIROGLU, J. Turkish preservice science teachers' efficacy beliefs regarding science teaching and their beliefs about classroom management. Teaching and Teacher Education, 23 (5), 664-675, 2007.

GIBBS, C. Explaining effective teaching: selfefficacy and thought control of action. Journal, of Educational Enquiry, v.4, n.2, p.1-14, 2003.

LIN, H.; GORRELL, J.; TAYLOR, J. Influence of culture and education on U.S. and Taiwan preservice teachers' efficacy beliefs. Journal of Education Research, v.96. n 1. p. 37-46, 2002.

LOONEY, L. Understanding teacher's efficacy beliefs: the role of professional community. Dissertation - Doctor of Philosophy (Faculty of the Graduate School). Maryland: University of Maryland, College Park, 2003.

PEREIRA, A. L.; ALMEIDA, P. C. A.; AZZI, R. G. A dimensão teórico-prática da psicologia educacional na formação de professores: a metodologia da problematização como desencadeadora da articulação entre teoria e prática. In: AZZI, R. G.; SADALLA, A. M. F. A. Psicologia e formação docente: desafios e conversas. São Paulo: Casa do Psicólogo, 2002.

PÉREZ GALLARDO, J. S. Formação profissional do licenciado em Educação Física: atuação profissional nas instituições de pré-escola e quatro primeiras séries do ensino de primeiro grau e na comunidade. Anais... Foz do Iguaçu: I Congresso Latino-Americano e II Congresso Brasileiro de Educação Motora,1998.

POLYDORO, S.; WINSTERSTEIN, P. J.; AZZI, R. G.; DO CARMO, A. P.; VENDITTI JR, R. Escala de auto-eficácia do professor de Educação Física. In: MACHADO, C.; ALMEIDA, L. S.; GONÇALVES, M.; RAMALHO (orgs). Avaliação Psicológica: formas e contextos. Braga: Psiquilíbrios edições. 2004. p. 330-337.

RANGEL-BETTI, I.C.; GALVÃO Z. Ensino reflexivo em uma experiência no ensino superior em Educação Física. Revista Brasileira de Ciências do Esporte, v.22. n³. p.105-106, 2001.

ROSS, J. A. Strategies for enhancing teachers' beliefs in their effectiveness: research on a school improvement hyphothesis. Teachers College Record. v.97, n 2. p. 27-51, 1995.

SPSS. Statistic package for the social scienses. Base 12.0 user's guide. Chicago: SPSS, 2003.

TANI, G. Vivências práticas no curso de graduação em Educação Física: necessidades, luxo ou perda de tempo? Caderno Documentos, São Paulo, 2, p. 1-22, 1996. 
TSCHANNEN-MORAN, M. e WOOLFOLK HOY,

A. Teacher Efficacy: Capturing an Elusive Construct. Teaching and Teacher Education, v.7, p.783-805, 2001.

TSCHANNEN-MORAN, M., WOOLFOLK HOY, A. The Influence of Resources and Support on Teachers' Efficacy Beliefs. Paper presented at the Annual Meeting of the American Educational Research Association. New Orleans, April, 2, 2002.

TSCHANNEN-MORAN, M., WOOLFOLK HOY, A. The differencial antecedents of self-efficacy beliefs of novice and experienced teachers.

Teaching and Teacher Education, v.23, n.6, p.944-956, 2007.

TSCHANNEN-MORAN, M., WOOLFOLK HOY, A., HOY, W.K. Teacher efficacy: its meaning and measure. Review of Educational Research, v.68, n.2, p.202-248, 1998.

VENDITTI JR., R. Análise da auto-eficácia docente de professores de educação física. Dissertação (Mestrado em Educação Física). Faculdade de Educação Física, Campinas: Unversidade Estadual de Campinas, 2005.

WATTERS, J.J., GINNS, I.S. Experiences of Novice Teachers: Changes in Self-Efficacy and Their Beliefs about Teaching. Paper presented at the Annual Meeting of the American Educational Research Association, New York, April, 1996.

WOOLFOLK HOY, A.E. What do teachers need to know about self-efficacy. Paper presented at Annual Meeting of the American Educational Research Asociation. San Diego, April, 2004. Disponível em:

http://www.emory.edu/EDUCATION/mfp/effpage.h

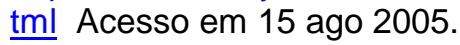

WOOLFOLK HOY, A., BURKE SPERO, R. Changes in teacher efficacy during the early years of teaching: A comparison of four measures.

Teaching and Teacher Education, v.21, n.4, p.343-356, 2005.
Endereço:

Roberto Tadeu laochite

DEF - Universidade de Taubaté

Av. Tiradentes, 500. Centro

Taubaté SP Brasil

12030-180

Telefone: (12) 3625.4275

e-mail: rotadiaochite@yahoo.com.br

Recebido em: 23 de outubro de 2009.

Aceito em: 14 de junho de 2010.

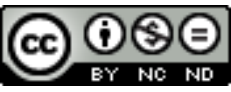

Motriz. Revista de Educação Física. UNESP, Rio Claro, SP, Brasil - elSSN: 1980-6574 - está licenciada sob Licenca Creative Commons 